\title{
Questão agrária, migração temporária e superexploração: uma síntese a partir do Vale do Jequitinhonha
}

\author{
Cristiane Luíza Sabino de Souza ${ }^{1}$ \\ https://orcid.org/0000-0002-6044-619X \\ ${ }^{1}$ Universidade Federal de Santa Catarina, Departamento de Serviço Social, Programa de Pós-Graduação em Serviço Social, Florianópolis, \\ SC, Brasil
}

Questão agrária, migração temporária e superexploração: uma síntese a partir do Vale do Jequitinhonha

Resumo: Neste artigo, partindo da apreensão de que a questão agrária e a superexploração da força de trabalho são determinações fundamentais da extração de valor no capitalismo dependente brasileiro, ou seja, substanciam o movimento inerente à lei geral da acumulação de capital no Brasil, traremos o debate do processo de migração temporária de trabalhadores do Vale do Jequitinhonha, Minas Gerais (MG), como uma expressão da dinâmica da acumulação do capital assentada na manutenção do monopólio da terra. Tal dinâmica impõe a expropriação, a violência e a superexploração como meios de extração de valor, numa realidade na qual o subdesenvolvimento é a única forma possível de desenvolvimento. Metodologicamente, buscamos, dialogicamente, articular discussões teóricas elaboradas por autores de referência de modo a construir uma síntese que apresente as determinações mais concretas da migração temporária no Jequitinhonha, apreendida na totalidade das relações sociais que emanam da dependência estrutural brasileira.

Palavras-chave: Questão agrária. Migração temporária. Superexploração.

Agrarian issue, temporary migration and overexploitation: a synthesis from the Jequitinhonha Valley Abstract: This article is based on the concern that the agrarian issue and the overexploitation of the labor force are fundamental elements of the extraction of value in Brazilian dependent capitalism. These elements materialize the movement inherent to the general law of the accumulation of capital in Brazil. Therefore, the article brings the debate on the process of temporary migration of workers from the Jequitinhonha Valley, Minas Gerais, as an expression of the dynamics of the accumulation of capital based on the maintenance of the land monopoly. Such dynamics impose expropriation, violence and overexploitation as a means of extracting value, in a reality in which underdevelopment is the only possible form of development. The aim is to, dialogically, articulate theoretical discussions elaborated by renowned scholars in order to build a synthesis that presents the most concrete determinations of the temporary migration in the Jequitinhonha valley, seized in the totality of the social relations that emanate of the Brazilian structural dependence.

Keywords: Agrarian issue. Temporary migration. Overexploitation.

Recebido em 16.10.2017. Aprovado em 08.02.2018. Revisado em 05.06.2018.

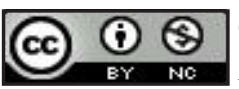

C O(s) Autor(es). 2018 Acesso Aberto Esta obra está licenciada sob os termos da Licença Creative Commons Atribuição-NãoComercial 4.0 Internacional (https://creativecommons.org/licenses/by-nc/4.0/deed.pt_BR), que permite copiar, distribuir e reproduzir em qualquer meio, bem como adaptar, transformar e criar a partir deste material, desde que para fins não comerciais e que você forneça o devido crédito aos autores e a fonte, insira um link para a Licença Creative Commons e indique se mudanças foram feitas. 


\section{Introdução}

Tomando por referência teórica central a Teoria Marxista da Dependência, compreendemos que no Brasil, assim como em toda a América Latina, é a dependência que explicita as particularidades do desenvolvimento desigual. Segundo Marini (2011, p. 141), a dependência deve ser entendida como "[...] relação de subordinação entre nações formalmente independentes, em cujo marco as relações de produção das nações subordinadas são modificadas ou recriadas para assegurar a reprodução ampliada da dependência". A dependência se reproduz no contexto em que a dominação imperialista, inerente ao capitalismo monopolista, define, na divisão internacional do trabalho (DIT), as funções de cada rincão do planeta na produção social geral da riqueza capitalista. A dependência, característica do capitalismo particular da América Latina, é indissociável do desenvolvimento em geral, cuja matriz desigual e combinada explicita a gênese e desdobramento histórico de dita condição.

$\mathrm{Na}$ dialética do desenvolvimento capitalista desigual e combinado, nos termos de Mandel (1985), o intercâmbio desigual permite aos países centrais drenarem as riquezas produzidas na América Latina e resolverem parte do problema estrutural de crise na acumulação de capital: a tendência à queda da taxa de lucro com a aceleração tecnológica (MANDEL, 1985). Por sua vez, as economias dependentes compensam internamente as perdas no âmbito externo, estabelecendo uma particular forma de exploração da força de trabalho - superexploração - e o uso irracional dos recursos naturais como mecanismos normais de produção de valor (MARINI, 2011; FERNANDES, 2006).

A superexploração, nos termos de Marini (2011), é a característica sui generis do capitalismo dependente, resultado do movimento particular da lei geral da acumulação capitalista nos países dependentes, os quais, inseridos num processo de troca desigual, têm na superexploração um mecanismo de compensação. Marini (2011, p. 149) identifica três mecanismos que a conforma como a "[...] intensificação do trabalho, prolongamento da jornada de trabalho e a expropriação de parte do trabalho necessário ao operário para repor sua força de trabalho".

Frente à primazia da propriedade privada, o desigual acesso à terra, aos meios de produção e ao poder, condicionam a apropriação da riqueza produzida, o pagamento de salários abaixo do nível de sobrevivência dos trabalhadores e de saqueio dos recursos naturais, uma vez que o passado colonial consolidou a matriz da acumulação primitiva de capital atrelada à apropriação privada da terra, que será legalizada no período da independência formal. Assim, a questão agrária se consolida como um processo necessário a acumulação do capital e se aprofunda de forma arraigada ao processo de acumulação sob a égide do capitalismo monopolista e sua atualidade altamente financeirizada (TRASPADINI, 2016).

De acordo com Kautsky (1968), a questão agrária integra a forma-conteúdo do capitalismo geral e, dada a dialética do desenvolvimento desigual e combinado, compreendemos que esta se apresentará, nas particularidades do capitalismo dependente, como um elemento que aprofunda ainda mais a desigualdade inerente à relação entre capital e trabalho na América Latina. O monopólio privado das terras, a superexploração da força de trabalho e a espoliação dos recursos naturais apresentam-se como fundamentos da dialética da dependência, desdobramento do intercâmbio desigual, que proporciona a transferência de valor, e da continuidade do processo de acumulação e valorização do capital (MARINI, 2011; FERNANDES, 2008). Assim a desigualdade também se diversifica e se aprofunda dentro das próprias fronteiras dos países, ditando a cada região a função da terra e do trabalho na dinâmica geral do desenvolvimento do capitalismo dependente, que arrasta consigo o subdesenvolvimento, seu irmão gêmeo siamês inseparável.

A ideologia do desenvolvimento como sinônimo de modernização, urbanização, tecnificação, é a mesma que oculta, intencionalmente, a essência da relação desigual - e de drenagem de recursos similar ao que ocorre de fora para dentro - entre as regiões brasileiras consideradas desenvolvidas e dotadas de progresso e aquelas tidas como subdesenvolvidas e fracassadas, como é o caso do Vale do Jequitinhonha'. Essa tipologia classificatória burguesa esconde a natureza sócio-histórica do desenvolvimento desigual e combinado inerente à gênese e desenvolvimento do capital, oculta a questão agrária no país e criminaliza a luta dos trabalhadores rurais pela terra, pelo trabalho livre e pela dignidade.

$\mathrm{Na}$ região do Vale do Jequitinhonha, as contradições do desenvolvimento capitalista dependente escancaram, no ideário do desenvolvimento, o subdesenvolvimento, processo que conforma um estigma sobre a região como a mais miserável do país. Nesta região, as contradições do desenvolvimento capitalista dependente e a questão agrária encarnam uma realidade histórica que impõe aos trabalhadores às mais precárias condições de reprodução, e de forma ainda mais brutal à parcela expressiva destes trabalhadores que vive no campo. O cerco capitalista das terras e a omissão do Estado - omissão entendida como ação e intenção (MARTINS, 1980) - projetam aos trabalhadores rurais da região a realidade dividida entre a reprodução camponesa e o trabalho assalariado nos grandes centros do agronegócio, mediada pela migração temporária. 
Para explicitar as vinculações entre a dinâmica geral da acumulação do capital no capitalismo dependente, a questão agrária, a migração temporária e a superexploração, apresentaremos, além desta introdução e da conclusão, em outras duas partes: 1) uma discussão sobre as migrações temporárias e a determinação da questão agrária sobre este processo, de modo a explicitar a relação indissociável entre ambas; 2) apresentaremos os elementos mais atuais da questão agrária no Vale do Jequitinhonha sob a égide do agronegócio, de modo a explicitar as condições objetivas dos trabalhadores e da luta de classes nesse contexto.

\section{Questão agrária e migração temporária de trabalhadores do campo: os caminhos da superexploração}

Para Martins (1973), a migração evidencia que a própria sociedade de origem está mergulhada num processo de transformação social que provoca o desencontro entre os sujeitos e as mudanças que estão ocorrendo. Historicamente, as mudanças e a reorganização da produção no campo brasileiro imbricam alterações na organização do processo de trabalho e, consequentemente, da força de trabalho. A migração, portanto, constitui um processo social que deriva das mudanças impostas aos trabalhadores pela dinâmica do capital na sua busca constante pela autovalorização.

O contraditório movimento do capital em geral e suas expressões no campo brasileiro em particular, cria duas realidades aparentemente distintas, mas substantivamente complementares em seu antagonismo - contradição inerente ao movimento de transformação dos pequenos produtores rurais em trabalhadores rurais

A ideologia do
desenvolvimento como
sinônimo de modernização,
urbanização, tecnificação, é a
mesma que oculta,
intencionalmente, a essência
da relação desigual - e de
drenagem de recursos similar
ao que ocorre de fora para
dentro - entre as regiões
brasileiras consideradas
desenvolvidas e dotadas de
progresso e aquelas tidas
como subdesenvolvidas e
fracassadas, como é o caso
do Vale do Jequitinhonha.
assalariados: 1) A expansão do agronegócio, centrado na produção de commodities e comandado principalmente pelo capital financeiro internacional, que direciona a produção agrícola no país e impõe como requisito um padrão de produção centrado no monocultivo, na crescente monopolização da terra e dos recursos produtivos e no controle do trabalho e da dinâmica reprodutiva dos trabalhadores do campo (BARTRA, 2006, DELGADO, 1985; MARTINS, 1986); 2) A possibilidade de manutenção do campesinato enquanto uma parcela de produtores diretos em pequenas propriedades, porém, em condições cada vez insuficientes para garantir sua reprodução individual e familiar apenas com o trabalho na unidade camponesa, o que, por um lado o obriga a se submeter à primazia da mercadorização da força de trabalho, e, por outro, o projeta como sujeito político que faz enfrentamento e resistência, no nível do cotidiano ou da organização política, aos desmandos do capital (BARTRA, 2006; MARTINS, 1986). Vale ressaltar que, a partir destes autores, identificamos como camponês determinada parcela da classe trabalhadora rural, pequena proprietária ou arrendatária de terras e não assalariada, cuja organização do trabalho se dá, na maioria das vezes, de modo familiar.

Ao abordarmos esses dois distintos processos sociais de organização do trabalho no campo e de relação com a natureza, no seio de uma sociedade subjugada à lógica do capital, estamos, necessariamente, tratando da disputa por terra e trabalho travada entre as antagônicas classes sociais que compõem esta sociedade. Tal disputa determina a questão agrária no Brasil e se manifesta diversificadamente em diferentes tempos e espaços.

Outro elemento que terá graves repercussões sobre a classe trabalhadora: a articulação entre os interesses dos latifundiários brasileiros e o capital estrangeiro com o apoio e financiamento do Estado. Essa é uma associação que exigiu um novo patamar de organização econômica no qual o avanço da ocupação territorial pelo capital se torna central. Este processo, já delimitado no período da ditadura militar, demarcou o aprofundamento da apropriação privada da terra. Principalmente a partir da década de 1970, a expansão das fronteiras agrícolas que visava garantir recursos estratégicos para o funci- 
onamento da economia nacional, mas principalmente para atender os interesses imperialistas. Coube ao Estado brasileiro um papel importante na mediação da aliança de interesses das classes dominantes internas e externas. Este forjou os mecanismos formais e os subsídios financeiros necessários para a expansão da dominação capitalista por áreas que até então não representavam grande importância para a economia nacional (SILVA, 1999; STEDILE, 2011).

No Vale do Jequitinhonha, a intervenção do Estado por meio da legislação pró-desenvolvimentista, desde a década de 1970, ocultou um processo de violência no qual uma grande leva de camponeses perdeu a posse das terras, os meios de trabalho e reprodução, os vínculos comunitários e a própria identidade camponesa (MOURA, 1988; SILVA, 1999). Os trabalhadores foram obrigados a assumir um novo modo de vida totalmente subordinado à lógica da modernização em curso no país, de forma paulatina foram transformados em população sobrante, em desempregados, em peões-do-trecho, em andarilhos. Estes engrossaram o exército industrial de reserva e somaram a oferta de mão-de-obra sobrante nas cidades, reforçando o mecanismo central de rebaixamento dos salários pelo capital. Tal transformação denota um processo brutal que, de acordo com Silva (1999, p.72), “[...] mesmo não se verificando a violência aberta, outros tipos fizeram-se sentir por meio da lei, ou mesmo pela violência simbólica".

Os deserdados da terra (MOURA, 1988), superexplorados e oprimidos pelas novas relações de produção, passaram a migrar temporariamente para atender a uma nova demanda do capital, a mão de obra para monocultura nas regiões em grande desenvolvimento agrícola do Estado de São Paulo, especialmente a região de Ribeirão Preto. Essa nova categoria não englobava apenas os homens, mas muitas vezes, também, mulheres e crianças, todos submetidos à superexploração e aos mais variados tipos de discriminação. A migração temporária é uma das expressões da reconfiguração do capital na região e representa a conformação de uma nova relação com a terra e com o trabalho.

O processo de migração temporária de trabalhadores do Vale do Jequitinhonha principalmente para trabalhar na colheita no Estado de São Paulo, constitui, por um lado, um mecanismo contraditório de manutenção da condição camponesa, por outro lado, coincide com a demanda de mão de obra barata necessária à expansão agrícola que se realizava, sobretudo, a partir dos canaviais paulistas (LEITE, 2010; SILVA, 1999).

Os trabalhadores, obrigados a tocar sua vida de acordo com o ciclo da grande produção agrícola, são como As andorinhas. Nem cá. Nem lá. Esta metáfora, utilizada por Silva (1998), foi dita por uma trabalhadora migrante sazonal que expressa aí sua história de vida e a muitos outros trabalhadores e trabalhadoras migrantes temporários. História esta permeada pelo sofrimento tanto dos que vão, quanto dos que ficam. É a história da perda da identidade camponesa, da tradição e da relação com a terra; a história das viúvas de marido vivo, dos órfãos temporários, da degradação do trabalhador que tem sua saúde e seu tempo de vida reduzidos pelo pesado trabalho na cana-de-açúcar. Mas é também a história da resistência aos desmandos do capital que submete seres humanos às condições de vida desumanas. É a história daqueles que mesmo oprimidos e superexplorados encontram caminhos de luta contra a dominação burguesa, na esperança de que a dominação territorial como propriedade privada do capital se torne passado (MOURA, 1988; SILVA, 1999).

A migração temporária é a forma mais dramática de migração. Segundo Martins (2002), é a mediação de um processo de desenraizamento que impulsiona um conjunto de transformações que envolvem trabalhadores que migram, àqueles com quem os migrantes se interagem no processo de trabalho e os que permanecem na região de origem. $\mathrm{O}$ desenraizamento modifica o cotidiano da origem e do destino, e nem um, nem outro pode permanecer o mesmo frente à mobilidade destes trabalhadores, que, ainda sendo temporária, é permanente, como afirma Maria Aparecida de Moraes Silva (2007). Nesse sentido, o processo de desenraizamento do trabalhador do campo tende a ser definitivo, encaminha para a sua subordinação direta às relações do grande capital.

Pelo acima exposto, reforçamos que a compreensão das configurações da migração temporária e dos processos migratórios como um todo, ontem e hoje, só pode dar-se tendo em vista que aquelas transformações estão inscritas no movimento global do desenvolvimento desigual e combinado do capital (MANDEL, 1985), o qual modifica também as próprias configurações dos processos migratórios como um todo e, particularmente, da migração temporária. Desvendar as raízes das contradições que a impulsionam, bem como suas próprias transformações ao longo do tempo pode nos permitir uma maior apropriação acerca do movimento de dominação do capital sobre o trabalho no Brasil, particularmente nas regiões consideradas subdesenvolvidas, como é o Vale do Jequitinhonha. Enfatizamos, portanto, que a migração temporária, como meio encontrado pelos trabalhadores do Vale do Jequitinhonha para garantirem a sobrevivência própria e de suas famílias, é resultado das transformações do capitalismo no campo brasileiro sob o capitalismo dependente, cuja reprodução, historicamente, acentua a questão agrária e a superexploração da força de trabalho.

Martins (1986) salienta que é o cerco capitalista das terras no Brasil que modifica as condições de vida e subsistência dos trabalhadores camponeses e os obriga a se inserirem num processo de assalariamento como complemento da subsistência própria e da família. Seja porque estes trabalhadores passam a pagar a renda da 
terra aos proprietários capitalistas ou porque têm suas terras de trabalho invadidas pelo capital. Assim, ao mesmo tempo, o cerco capitalista retira-lhes as condições de se reproduzirem e sobreviverem apenas do campesinato e coloca-lhes o assalariamento como complemento da subsistência. Isto quando não os expulsa definitivamente de suas terras e os lança nas favelas e aglomerados urbanos. A migração temporária é a mediação entre a reprodução camponesa e o trabalho assalariado desses trabalhadores. É também uma mediação que permite ao capitalista uma maior apropriação sobre o resultado do trabalho, mantendo níveis extremos de superexploração desta força de trabalho (MARINI, 2011; MARTINS, 1986).

De maneira mais explícita: o cerco capitalista obriga os camponeses a se inserirem como assalariados em processos produtivos agrícolas em outras regiões do país onde a grande produção agrícola capitalista se estabelece. É o ciclo de produção da grande lavoura capitalista que define o período no qual estes trabalhadores devem migrar em busca de trabalho assalariado, ainda que para isto ele tenha que deixar para trás, na sua região de origem, a produção e o trabalho geral na unidade camponesa e a subsistência familiar nas costas da mulher e dos filhos menores. Por outro lado, ao ter parte da subsistência própria e da família ancorada na produção familiar (trabalho da mulher e dos filhos) este trabalhador fica à disposição do capitalista sem que este tenha que dispensar todo o capital necessário à reprodução de sua força de trabalho (MARTINS, 1986; SILVA, 1999). "É verdade que o salário recria, no operário, o camponês; que por sua vez recria o operário." (MARTINS, 1986, p. 53). A nosso ver, a superexploração dessa força de trabalho, cuja reprodução é mediada pela migração temporária, ganha aqui um elemento de aprofundamento.

A relação entre o trabalho da família camponesa e o trabalho assalariado do migrante na reprodução da força de trabalho como um todo é desigual à medida que o salário apenas complementa a reprodução do migrante e sua família como força de trabalho, enquanto a produção camponesa recria o camponês como operário inteiro, pronto para ser explorado pelo capital. Para Martins (1986, p. 54) “[...] o capital não paga, assim, o preço da formação da mão-de-obra de que necessita. Quem paga esse preço é a família camponesa”. E é esse trabalho familiar não pago que permite ao capitalista uma apropriação ainda maior da mais-valia produzida pelo trabalho através do salário deste trabalhador em níveis extremos.

No capitalismo dependente, onde a subordinação do País aos ditames imperialistas determinam o que e como produzir, a dependência tecnológica e o intercambio desigual encontram na abundante oferta de força de trabalho os mecanismos para compensar a posição subalterna e desigual no mercado mundial (TRASPADINI, 2016). Segundo Martins (2002), resulta da superexploração da força de trabalho um processo de reequilíbrio fictício das condições médias de produção, historicamente desiguais, condenando os trabalhadores a situações miseráveis de reprodução da vida, e destes, os migrantes que trabalham na produção agrícola são os que mais sofrem.

\begin{abstract}
Alguns processos característicos do desenvolvimento capitalista recente no Brasil estão relacionados com esta dimensão da realidade. José Graziano da Silva demonstrou num de seus estudos, que o aparecimento do chamado "boia fria" (no sudeste e no sul) ou "clandestino" (no nordeste canavieiro) está diretamente relacionado com a modernização incompleta do processo de produção. Há momentos desse processo, que, por motivos técnicos, permanecem desproporcionalmente dependentes de trabalho humano e de formas atrasadas de utilização da força de trabalho. O uso da força de trabalho fica desproporcionalmente concentrado em momentos específicos do processo de produção, como a colheita do café ou do corte da cana. [...] Ao mesmo tempo, o trabalho é intensamente substituído em outros momentos do processo de produção por máquinas e equipamentos modernos, conhecimento técnico e científico, defensivos, herbicidas, etc. Enfim, o trabalho é substituído por meios poupadores de trabalho. [...] Surgiu o emprego sazonal e precário, isto é, na verdade, o desemprego sazonal, as migrações temporárias, os traficantes de mão-de-obra e todos os problemas sociais decorrentes, (MARTINS, 2002, p. 157-158).
\end{abstract}

De acordo com Martine (1982), as migrações temporárias de trabalhadores rurais, que se abriram como um novo tipo de mobilidade do trabalho no Brasil, principalmente a partir da década de 1970, é um tipo de migração cujas informações são pouco buscadas e trabalhadas pelas fontes tradicionais de informações demográficas, como as pesquisa do tipo Censo, PNAD (Pesquisa Nacional por Amostra de Domicílios) ou Survey. As informações levantadas por estas fontes pouco têm a dizer sobre a complexidade das migrações temporárias, exatamente porque não trazem elementos que possibilitem compreender as especificidades de grupos e espaços migratórios em seu movimento constante, pois estão centradas nos elementos origem e destino (MARTINE, 1982; MARTINS, 1986, 2002).

Para Martins (1986), a migração temporária está sempre em movimento. E esse movimento é mais do que ir e retornar, porque os lugares e os sujeitos envolvidos neste processo estão em mudança constante em paralelo ao processo de migração e em decorrência dele. Para Silva (1999), as migrações temporárias se tornam permanentes, a medida que o processo que a impulsiona - avanço do capital sobre as 
condições de reprodução camponesa - está em contínuo crescimento. Nesse sentido, o que explicita seu movimento é a própria mobilidade permanente do camponês migrante que, no entanto, não se move socialmente no sentido de se integrar completamente a um novo espaço. Ele tem uma fixação sociológica a um lugar, representativa daquilo que ele só vive em um período, o da entressafra. Mas para o trabalhador aquele é o seu lugar. É a memória e o pertencimento que, dadas as impossibilidades de integração ao novo ou apenas a sua integração marginal, o permite ter por referência a socialização do seu lugar de origem, ainda que esta seja também temporária.

Silva e Menezes $(2008$, p. 8) sugerem a análise da migração temporária “[...] como um acontecimento histórico, que atinge os(as) que partem e os(as) que ficam, constituído por elementos objetivos, estruturais, ideológicos, culturais e subjetivos, vis-à-vis as organizações sociais de classe, gênero e raça/etnia”. Assim, este tipo de migração, enquanto um processo social de mediação de transformações no cotidiano e na reprodução social dos sujeitos nele envolvidos, se difere de outros tipos de migração. Consideramos, portanto, para a análise do processo de migração temporária dos trabalhadores rurais do Vale do Jequitinhonha, as suas manifestações desde o lugar de origem, cuja organização do trabalho é o campesinato; o lugar de trabalho temporário, definido pelo agronegócio; assim como o constante movimento que circunda a produção e a reprodução da vida social desses e nesses lugares. Partir deste movimento significa considerar as condições de superexploração, de risco, de discriminação, de marginalização e de violência que vivenciam, não só os migrantes temporários, mas diversas categorias de migrantes internas e externas. É considerar também as contraditórias mudanças impostas pelo avanço do capital sobre a terra, o acirramento da questão agrária pela expropriação, espoliação e degradação dos recursos naturais e da capacidade produtiva da terra e do trabalho, dentro e fora do Vale.

Maria Aparecida de Morais Silva (1999), em seu livro Errantes do fim do século, traça de maneira ampla e comprometida o histórico das migrações temporárias dos trabalhadores do Vale para os canaviais paulistas e também para a colheita de café e laranja no mesmo estado. A inserção destes trabalhadores em processos brutais de superexploração, no qual a sua submissão às mais precárias relações de trabalho e sociabilidade e, ao mesmo tempo, à falta de alternativas à migração temporária deixaram marcas profundas na vida e na memória de tantos trabalhadores da região. A migração temporária para os canaviais paulista manteve-se forte até a década de 1990, sendo a alternativa de assalariamento encontrada, principalmente, pelos jovens, vez que, o extenuante trabalho no corte de cana logo esgota a capacidade laboral dos trabalhadores e exige uma constante renovação da força de trabalho (LEITE, 2010). A partir dos anos 2000, sob a égide do chamado agronegócio, a intensificação da produção primário-exportadora coloca novos desafios aos trabalhadores do Vale, tanto pelas modificações nas grandes lavouras capitalistas - com a automação, a nova expansão da fronteira agrícola, etc. - quanto pela acentuação do cerco capitalista sobre suas terras na região, impulsionada pela construção de hidrelétricas, pela mineração e pela expansão dos desertos verdes de eucalipto, iniciada na década de 1970.

Sob o agronegócio a questão agrária no Brasil e, em particular, no Vale, se acentua drasticamente, aumentando os conflitos, a violência, a incerteza e instabilidade dos trabalhadores camponeses sobre a sua reprodução. Como apresentaremos no próximo tópico, a questão agrária na região, na atualidade, sintetiza o acirramento de um largo processo de expropriação, exploração e marginalização dos trabalhadores no campo. Para tais trabalhadores o agro não é pop ${ }^{2}$, é, antes, o monstro devorador da vida da terra e da vida da gente que necessita da terra.

\section{A questão agrária no Vale do Jequitinhonha hoje: o acirramento da expropriação camponesa sob a égide do agronegócio}

No contexto atual da produção primário-exportadora no Brasil, correspondente à histórica inserção dependente do País na divisão internacional do trabalho, a intensificação de tal produção obedece, como nunca, ao movimento global do capital financeiro-imperialista. A dominação das empresas estrangeiras, a espoliação da terra e dos recursos naturais e a brutal violência com o território e a superexploração de sua gente, são o retrato do agronegócio em todo o país. Nesse cenário, o conjunto social de referência do migrante que se desloca (MARTINS, 2002) do Vale do Jequitinhonha, expõe cada vez mais a fratura aberta pela questão agrária e o cerco capitalista que estabelece formas de extração de valor ainda mais acentuadas sobre o trabalho dos que permanecem na região.

O processo de diferenciação do camponês a partir das relações de produção não mediadas pelo assalariamento, enquanto se constituem como produtores diretos, mas mediadas pela mercadoria, o coloca cada vez mais submisso ao capital, que se movimenta paulatinamente sobre a reprodução destes trabalhadores 
e projeta a expropriação como um processo manifesto (LEITE, 2015). O cerco do grande capital financeiro sobre o trabalho no campo, na região, se manifesta a partir da submissão do processo de reprodução dos trabalhadores à economia política do agronegócio, à produção de commodities agrícolas e minerais e à geração de energia para a sua produção em outras regiões.

Sob a hegemonia do capitalismo monopolista financeiro, particularmente no século XXI, O cativeiro da terra (MARTINS, 1998a) expressa a continuidade da superexploração da força de trabalho no campo e na cidade e expõe, portanto, a expropriação, a opressão e a crescente miséria da classe trabalhadora em concomitância com o processo de acumulação de capital nas mãos de uma minoria. Ao avançar sobre as terras e sobre os recursos produtivos, o capital financeiro aprofunda a necessidade de cultivar a renda da terra para o processo de valorização e acirra todas as contradições inerentes ao capitalismo geral e dependente. A dominação econômica e política do agronegócio expõem a classe trabalhadora do campo a uma extração de sobretrabalho cada vez maior ao apropriar-se de parte gigantesca do excedente econômico socialmente produzido e apropriado de forma privada. Isto ocorre tanto pela superexploração do trabalhador assalariado, como pela subordinação do camponês aos ditames do mercado.

A realidade dos trabalhadores migrantes temporários do Vale do Jequitinhonha é uma expressão desse avanço. Estes trabalhadores e trabalhadoras sentem na própria pele - também literalmente - os impactos da questão agrária aberta e latente no país. Dentro e fora do Vale, o avanço do capital afunila cada vez mais as condições de reprodução e força-os a um destino de retirantes, de boias frias, de marginalizados, de sem terras e sem tetos.

Para os trabalhadores que encontram a migração temporária como a única saída para a sobrevivência, a superexploração apresenta caráter ainda mais violento, e configura um processo onde a espoliação econômica do trabalhador é profundamente acrescida por mecanismos de dominação de sua vida, dentro e fora das usinas canavieiras. Para estes, a dignidade e a cidadania garantida, em termos burgueses, pelo emprego formal, não se fazem reais. Mesmo para aqueles sob a contratação formal, dentro da legislação trabalhista, a manipulação das empresas sobre as formas de pagamento e de realização do trabalho, avança sobre sua condição humana, aprisiona sua subjetividade e os mantêm reféns de uma lógica produtiva que só pode existir por intermédio da superexploração.

Destacamos que para captar a dinâmica da superexploração, mediada pelas migrações na sua totalidade, é necessário situá-la na sua dinâmica concreta, como expressão da luta de classes. Para tanto, compreender a dinâmica interna das regiões originárias dos trabalhadores migrantes é essencial. O movimento do atual cerco capitalista na região reatualiza a apropriação da renda da terra pelo capital financeiro e coloca os trabalhadores em situações cada vez mais miseráveis de reprodução, retroalimentado a dinâmica da criação de uma população excedente e sua mobilidade para ser superexplorada em outras regiões.

De acordo com Zhouri e Zucarelli (2010) as atividades reflorestadoras, mineiras e hidrelétricas, que são parte dos projetos de desenvolvimento implantados no Vale desde a década de 1970 e que se ampliam ainda mais sob a égide da reprimarização da economia nacional pós anos 2000, são as formas hegemônicas de expropriação da terra pelo grande capital na região. A apropriação da terra e dos recursos naturais do Jequitinhonha e a precarização do trabalho, com crescente voracidade, pelo capital financeiro exerce uma pressão imensa sobre a reprodução dos trabalhadores no campo. Há no presente novas formas de apropriação das terras pelo capital que não são diretas em termos de posse legal. O cerco exercido pelas grandes empresas, por meio de formas extrativistas predatórias, mediadas por contratos de vendas de mercadorias determinados pelas empresas, compromete a sobrevivência destes trabalhadores, cujo solo e águas são contaminados, destruídos ou inviabilizados enquanto meio de produção da vida.

A expropriação, direta ou paulatina, reitera a sina dos retirantes, forçando os trabalhadores à migração como única saída, num momento em que a mobilidade geográfica da força de trabalho já não leva a lugar nenhum. De acordo com Martins (2002), a ascensão social, historicamente ligada aos processos migratórios não aparece mais como perspectiva, em seu lugar a perspectiva é a da mera sobrevivência, e é por ela que os sujeitos se movem uma vez esgotadas as condições de reprodução nos seus lugares de origem.

A diferença com as transformações positivas que as migrações possam promover, e de certo modo promoveram no passado e ainda residualmente promovem, está no fato de que são migrações que desagregam sem transformar; dessocializam, mas não ressocializam, não preparam nem reeducam para uma sociabilidade mais rica e humanizadora. Deixam aberto o espaço para formas precárias e socialmente problemáticas de ajustamento recíproco das pessoas na socialização espontânea dos ambientes degradados. Vão definindo uma sociabilidade dominada não só pela miséria moral. O que foi frequentemente um período de transição e de provisória acomodação numa nova situação, vem se transformando num modo permanente de vida, num modo de vida sem qualidade e sem estilo, sem alegria e sem beleza (MARTINS, 2002, p. 141). 
Há na atualidade uma inversão no sentido das migrações num geral, não somente da temporária: “Antes migrava-se para subir na vida. Agora migra-se para atenuar a queda e muitas vezes já se migra como parte de um processo de queda". (MARTINS, 2002, p. 148).

\section{Considerações finais}

Neste breve trabalho, ao expor a realidade do Jequitinhonha mediada pelos debates da questão agrária e da migração temporária, o que buscamos evidenciar é que o sofrimento dos trabalhadores do Vale, dentro e fora da região, está geneticamente ligado ao processo de expansão e dominação do capital sobre o trabalho de modo geral. É a dinâmica desigual e combinada do capital que direciona, no capitalismo dependente, a condição de subdesenvolvimento de regiões como o Vale do Jequitinhonha e, nas suas configurações atuais, aprofunda a questão agrária e impulsiona a migração temporária forçada como um dos mecanismos de aprofundamento daquela dominação.

A superexploração apresenta as mais brutais facetas, que vão desde a renda insuficiente para uma reprodução adequada da força de trabalho, ao adoecimento e a morte dos trabalhadores. "A morte ronda os canaviais paulistas" escreveu Silva (2006, p. 111), denunciando a brutalidade do trabalho na produção canavieira. Enquanto isso, a violenta expropriação de terras no Vale força, cada vez mais, famílias inteiras partirem do seu lugar de origem. É o cerco do capital e suas vitórias sobre o trabalho.

Mas a realidade do Vale nos mostra também que, ao mesmo tempo em que a violência da questão agrária força as migrações temporárias e definitivas, ao provocar rupturas no cotidiano dos sujeitos, modifica também suas percepções acerca da realidade na qual estão inseridos. A degradação de suas terras, do seu modo de vida e sua cultura, a cada avanço das forças produtivas do capital, ordena-lhes a ressignificação e a reinvenção desse cotidiano. E é nesse nível das relações sociais que se define a continuidade de sua sobrevivência e resistência aos imperativos do capital.

Pois é no instante dessas rupturas do cotidiano, nos instantes da inviabilidade da reprodução, que se instaura o momento da invenção, da ousadia, do atrevimento, da transgressão. E aí a desordem é outra, como é outra a criação. Já não se trata de remendar as fraturas do mundo da vida, para recriá-lo. Mas de dar voz ao silêncio, de dar vida à História. (MARTINS, 1998, p. 6).

No Vale do Jequitinhonha, a histórica marginalização como a região mais miserável do país retrata o resultado da dinâmica do capital sobre aquele território, no entanto, a anulação e esvaziamento do sentido da ocupação do território para a reprodução familiar e modos de vida particulares, não se dá sem conflitos e construções de mecanismos coletivos de resistência pelos sujeitos. O acirramento da questão agrária na região, pelo cerco capitalista, suscita enfrentamentos que,

[...] vão desde a denúncia formal em órgãos ambientais e jurídicos, passando pela busca de entidades de parceria e publicização do caso, até confronto direto com estratégias de paralização da degradação de seus territórios [...] movimenta uma gama de atores em defesa dos seus direitos, sejam comunidades ribeirinhas, quilombolas, indígenas ou camponesas que não se vêem beneficiadas por tais concepções desenvolvimentistas. (ZHOURI; ZUCARELLI, 2010, p. 233).

A luta pela terra e a reivindicação da reforma agrária nasce no Vale junto aos primeiros movimentos de expropriação dos posseiros. As ocupações e os conflitos decorrentes explicitam a omissão - ação e intenção do Estado e a violência, perpetrada tanto pelos órgãos oficiais, quanto pelos jagunços dos grandes proprietários. $\mathrm{O}$ Vale foi palco da primeira ocupação de terras em Minas Gerais - Fazenda Aruega, na cidade de Novo Cruzeiro no ano de 1988. Foi também palco de um dos piores massacres ${ }^{3}$ a trabalhadores sem terra no País - Fazenda Nova Alegria em Felisburgo, no Baixo Jequitinhonha, em 2004. No entanto, frente à violência, à negação do direito à terra e ao trabalho e à violação de tantos outros direitos, as dezenas de assentamentos, acampamentos e de movimentos sociais organizados, existentes na atualidade, mostram o movimento contra-hegemônico, realizado por aqueles que perderam suas condições de reprodução no campo, numa retomada da terra que, apesar de não os livrar da dominação do capital, demonstra o potencial de luta dos trabalhadores do Vale.

A organização da luta trabalhadora na região se apoia nas mais diversas entidades e movimentos como o MST, MPA, MAB, sindicatos rurais, associações de artesãos e de garimpeiros, ONGs e entidades culturais como a FECAJE, que realiza o FESTIVALE. Este, que é o maior festival cultural da região, para além do compromisso com a valorização da cultura tradicional dos vários grupos de congados, bois-de-janeiro, marujadas, corais, artesa- 
natos etc., tem se movimentado no sentido de colocar em debate as questões fundamentais vinculadas a que tipo de desenvolvimento se quer para a região, constituindo-se, portanto, numa importante trincheira de luta. E, assim, o Vale segue, sendo um vale de riquezas que não são valor nem valorizam o capital, antes, constituem-se em fiapos de esperança na construção coletiva e cotidiana da luta por uma sociedade mais justa.

Quando explicitamos a situação dos trabalhadores(as) do Vale frente ao avanço do capital, o acirramento da questão agrária, a violência, a expropriação e a migração forçada, buscamos retratar a realidade vivida por aquela região. Mas, compreendida na totalidade das relações sociais que a determinam como tal, a particularidade do Vale expressa, dialeticamente, o movimento total do capitalismo dependente, o qual reproduz em escala ampliada o desenvolvimento do subdesenvolvimento, como salientara Frank (1967). A realidade do Vale explicita os desafios da classe trabalhadora frente ao cerco predatório do capital em todo o país ontem e hoje, assim como expressa a trajetória de luta dos trabalhadores do campo por uma nova forma de viver. É por isso que afirmamos, por fim, que, mais do que nunca, faz-se urgente pautar o debate da questão agrária, desde as suas raízes, desnudando seus vínculos com o capital financeiro rentista e com a acumulação por espoliação (HARVEY, 2004) para que possamos desvendar a essência dos processos violentos que aparecem como crises políticas, econômicas, etc. e traçar, objetiva e subjetivamente estratégias de transformação radical desta sociedade bárbara.

\section{Referências}

BARTRA, A. El capital en su laberinto. De la renta de la tierra a la renta de la vida. México, D.F.: Universidad Autónoma de la Ciudad de México, 2006.

DELGADO, G. Capital financeiro e agricultura no Brasil. Campinas: Unicamp, 1985.

FERNANDES, F. A revolução burguesa no Brasil: ensaio de uma interpretação sociológica. 5. ed. São Paulo: Globo, 2006. . Sociedade de classes e subdesenvolvimento. 5. ed. São Paulo: Global, 2008.

FRANK, A. G. El Desarrollo del subdesarrollo. Pensamiento Crítico, Habana, n. 7, p. 159-173, ago. 1967.

HARVEY, D. O novo imperialismo. São Paulo: Loyola, 2004.

INSTITUTO BRASILEIRO DE GEOGRAFIA E ESTATÍSTICA. Censo demográfico 2010: características da população e dos domicílios: resultados do universo. Rio de Janeiro, 2011. Disponível em: <https://biblioteca.ibge.gov.br/visualizacao/periodicos/93/ cd_2010_caracteristicas_populacao_domicilios.pdf $>$. Acesso em: 20 ago. 2015.

KAUTSKY, K. A questão agrária. Rio de Janeiro: Laemmert, 1968.

LEITE, A. C. G. A modernização do Vale do Jequitinhonha Mineiro e o processo de formação do trabalhador "bóia-fria" em suas condições regionais de mobilização do trabalho. 2010. 337 f. Dissertação (Mestrado em Geografia) - Universidade de São Paulo, São Paulo, 2010.

O campesinato no Vale do Jequitinhonha: da sua formação no processo de imposição do trabalho à crise (sua) reprodução capitalista. 2015. 334 f. Tese (Doutorado em Geografia) - Universidade de São Paulo, São Paulo, 2015.

MANDEL, E. O capitalismo tardio. São Paulo: Nova Cultural, 1985.

MARINI, R. M. Dialética da dependência. In: TRASPADINI, R.; STÉDILE J. P. (Org.). Ruy Mauro Marini: vida e obra. 2. ed. São Paulo: Expressão Popular, 2011. p. 131-172.

MARTINE, G. Populações errantes e mobilidade da reserva de mão-de-obra no Brasil. In: SIMPÓSIO SOBRE CRESCIMENTO DEMOGRÁFICO NA BASE DA PIRÂMIDE SOCIAL, 1982, Campinas. Anais... Campinas: SBPC, 1982.

MARTINS, J. S. Expropriação e violência: a questão política no campo. 2. ed. São Paulo: Hucitec, 1980. O voo das andorinhas: migrações temporárias no Brasil. In: . Não há terra para plantar neste verão. Petrópolis: Vozes, 1986. p. 43-61. O cativeiro da terra. 7. ed. São Paulo: Hucitec, 1998a.

. A sociedade vista do abismo: novos estudos sobre exclusão, pobreza e classes sociais. 2. ed. Petropólis: Vozes, 2002. . A imigração e a crise do Brasil agrário. São Paulo: Pioneira, 1973.

. O senso comum e a vida cotidiana. Tempo Social, São Paulo, v. 10, n. 1, p. 01-08, maio 1998b.

MOURA, M. Os deserdados da terra. Rio de Janeiro: Bertrand Brasil, 1988.

SILBY, A.; ABNER, G.; MARTINS, T. (Org.). GERAES: a realidade do Jequitinhonha. Reprodução fac-simile dos fascículos do periódico Jornal Geraes publicados entre 1978 e 1985. Belo Horizonte: NEOPLAN, 2011.

SILVA, M. A. M. As andorinhas. Nem lá. Nem lá. Cadernos CERU, São Paulo, n. 9, p. 29-44, 1998. Disponível em: <http:// www.revistas.usp.br/ceru/article/view/74985>. Acesso em: 03 jul. 2015.

. A morte ronda os canaviais paulistas. Revista da Associação Brasileira de Reforma Agrária, Rio de Janeiro, v. 33, n. 2, p. 111141, ago./dez. 2006.

. Errantes do fim do século. São Paulo: UNESP, 1999.

Lições do Vale: narrativa de uma pesquisadora. In: NOGUEIRA, M. D. P. (Org.). Vale do Jequitinhonha: ocupação e trabalho. 
Belo Horizonte: UFMG, 2013. p. 17-36.

. Trabalho e trabalhadores na região do "mar de cana e do rio de álcool”. In: NOVAES, J. F.; ALVES, F. (Org.). Migrantes: trabalho e trabalhadores no complexo agroindustrial canavieiro (os heróis do agronegócio brasileiro). São Carlos: EdUFSCar, 2007. p. 55-85. SILVA, M. A. M.; MENEZES, M. A. Migrações rurais no Brasil: velhas e novas questões. Brasília: Nead, 2008. Disponível em:<http:/ /www.faed.udesc.br/arquivos/id_submenu/1416/migracoes_rurais_no_brasil_velhas_e_novas_questoes.pdf $>$ Acesso em: 20 ago. 2015 . STEDILE, J. P. Introdução. In: STEDILE, J. P.; ESTEVAM, D. (Org.). A questão agrária no Brasil: o debate tradicional 1500-1960. 2. ed. São Paulo: Expressão Popular, 2011. p. 15-34.

TRASPADINI, R. S. Questão agrária, imperialismo e dependência na América Latina: a trajetória do MST entre novas-velhas encruzilhadas. 2016. 338 f. Tese (Doutorado em Educação) - Universidade Federal de Minas Gerais, Belo Horizonte, 2016.

ZHOURI, A.; ZUCARELLI M. C. Visões da Resistência: conflitos ambientais no Vale do Jequitinhonha. In: SOUZA, J. V. A.; HENRIQUES, M. S. (Org.). Vale do Jequitinhonha: formação histórica, populações e movimentos. Belo Horizonte: UFMG, 2010. p. 109-236.

\section{Notas}

1 O Vale do Jequitinhonha está localizado ao nordeste Estado de Minas Gerais e é composto por 55 municípios divididos em três microrregiões (Alto, Médio e Baixo Jequitinhonha). Ocupa uma faixa territorial de $53.572 \mathrm{Km} 2$. Possui uma população de aproximadamente 737.516 pessoas segundo o Instituto Brasileiro de Geografia e Estatística (2011), destas, 36,38\% estão no campo, 16,85\% estão em situação de extrema pobreza e 29,87\% são beneficiárias do Programa Bolsa Família. A agricultura familiar tem grande expressão na região somando 42.947 estabelecimentos; conta ainda com 674 pescadores registrados, 30 comunidades quilombolas reconhecidas e 1110 famílias assentadas. É apresentada como a região mais miserável do país (SILBY; ABNER; MARTINS, 2011) pela grande mídia e órgãos governamentais, que não evidenciam a dinâmica real da região frente ao cerco do capital e ao subdesenvolvimento por este imposto.

2 Aqui fazemos alusão à campanha publicitária da Rede Globo de televisão que exerce a função de difusão da ideologia do agronegócio com a chamada Agro é pop. Agro étec. Agro é tudo, amplamente reproduzida durante a sua programação.

3 O massacre realizado por 15 homens armados executou cinco trabalhadores rurais e ainda feriu a bala outras 12 pessoas - dentre eles uma criança - queimou a escola local e vários barracos, deixando centenas de famílias somente com a roupa do corpo no acampamento Terra Prometida, na fazenda Nova Alegria, em Felisburgo (MG), em 20 de novembro de 2004. Foi um dos casos que mais teve repercussão na mídia dada a prosternação da justiça e revela a violência e a impunidade.

\section{Cristiane Luíza Sabino de Souza}

crisabino1@hotmail.com

Mestre em Política Social pelo Programa de Pós-Graduação em Política Social da Universidade Federal do Espírito Santo (UFS)

Doutoranda em Serviço Social pela Universidade Federal de Santa Catarina (UFSC)

\section{UFSC}

Campus Universitário Reitor João David Ferreira Lima - Trindade

Florianópolis - Santa Catarina - Brasil

CEP: 88.040-900

\author{
Agência financiadora \\ Não se aplica.
}

\section{Contribuições dos autores}

Não se aplica.

\section{Consentimento para publicação}

Não se aplica.

\section{Conflito de interesses}

Não há conflito de interesses.

Aprovação por Comitê de Ética e consentimento para parti-

cipação

Não se aplica. 